\section{Public Health Service}

\section{Emergency Assistance In Disaster Relief}

By Gordon E. McCallum, C.E., and Harvey F. Ludwig, M.S.

The principal public health problems created by natural disasters are due to the breakdown of public health safeguards resulting from damage to, and failure of, certain public works and other facilities and the interruption of public services upon which present-day urban communities have become almost totally dependent. Among examples which can be cited are facilities for maintaining a safe and adequate supply of water; facilities for collecting, treating, and disposing of sewage, garbage, and other community wastes; measures for controlling and protecting against rodents and insects which transmit disease; and procedures for maintaining food and milk free from contamination. Failure of such facilities or services reverts the community to virtually primitive conditions, or worse, because the individual has largely lost his knowledge of how to obtain and purify his own water supply, how to prepare food without fuel, how to dispose of his own wastes, or how to improvise temporary shelter. Unless emergency protective measures are promptly taken, there is great hazard of large-scale epidemics of communicable diseases. The seriousness of such situations is one of the basic reasons for the unique and powerful authority of the health officer in an American State or community.

The role of the Public Health Service at times of disaster is the provision of emergency assistance to stricken areas whenever their resources become taxed to the degree that a request for

Mr. McCallum is chief of health emergency planning, Office of the Surgeon General, Public Health Service. Mr. Ludwig is consultant for sanitary engineering on the health emergency planning staff. outside assistance becomes necessary. The assistance is provided through the State departments of health, as is other assistance by the Service. The Public Health Service has a long record of successfully providing such assistance: the yellow fever epidemic in Hampton, Va., in 1894 and in New Orleans in 1905; the plague outbreaks in San Francisco in 1907 and in New Orleans in 1914 and in 1920; the Mississippi River flood of 1927; the Ohio River flood of 1937; the gulf coast hurricane in 1947; the Texas City disaster of 1947; and the California encephalitis epidemic of 1952 . In every instance Public Health Service assistance has simply supplemented, as required, the regular State-community public health operation, in which the community, State, and Federal health officials function as a team on all sorts of problems. Voluntary health agencies have also aided in emergency activities, with the result that over the years a close collaboration has evolved between the Public Health Service and the American National Red Cross on the handling of emergency health problems.

\section{Policies Governing Emergency Activities}

In carrying out its emergency assistance activities, the Public Health Service makes available to the States its regular resources of professional personnel, hospitals, equipment, and supplies. Under extreme conditions it can arrange additional assistance through utilization of the Reserve Corps, by which needed specialists from outside the Government can be quickly mobilized and deployed to the sites of need.

The Public Health Service also has traditionally utilized its offices to help mobilize resources from outside the regular health agericies. Through the continuing contacts of its personnel with their professional counterparts in other government agencies, military and civilian, and in voluntary and private institutions and organizations, the Public Health Service is peculiarly able to render this type of assistance.

\section{The Kansas-Missouri Flood}

The Public Health Service's participation in emergency assistance during the Kansas-Mis- 
souri flood in the summer of 1951 was typical. When it became evident that a flood of disaster proportions was impending, the Surgeon General designated the Public Health Service regional medical director at Kansas City to supervise and coordinate Public Health Service activities. At the same time, the Communicable Disease Center dispatched necessary technicians and equipment to the flood area from various Communicable Disease Center field offices as well as from its headquarters at Atlanta. Technicians were made available also from the Public Health Service Missouri Drainage Basin Office and from miscellaneous other Public Health Service stations. During the period of the flood peak, some 70 Public Health Service specialists were assigned to duty in the flood area at the request of State health officials, including 3 medical officers, 23 sanitary engineers, 15 entomologists and other scientists, and 19 sanitarians. The work which they performed comprised emergency measures undertaken during the flood-peak period plus rehabilitation activities as the flood receded.

\section{Emergency Measures}

Of particular importance during the emergency was assistance in the restoration and maintenance of safe public water supplies. Portable water filtration and chlorinating equipment, some of which was flown into the area, was placed into use in communities where the normal water supplies had been temporarily inactivated, for example, at Ottawa, Kans., where the water supply plant was flooded out, and at Indian Creek in Johnson County, Kans., where the normal source of supply delivered from Kansas City had been interrupted. In other places, flooded pumping plants were dewatered and restored to service, and mains were disinfected with chlorine to eliminate contamination. Disinfecting chlorine compounds were furnished to residents in communities served by wells which had become flooded, for temporary use while the wells were being pumped out, sterilized, and returned to service. Arrangements were worked out with chlorine manufacturers to permit prompt shipment of extra supplies of liquid chlorine to the area had this become necessary. Special laboratory tests were made-for example, at the Lawrence (Kans.) State Laboratory - to guide the work and to insure the continued safety of water supplies which had been subjected to contamination. Considerable work was also done in reactivating interrupted sewage disposal works, including pumping plants, to prevent further contamination of water supplies.

Other work accomplished during the emergency period included assistance in the maintenance of safe food and milk supplies at evacuation centers, furnishing and distributing medical supplies, including vaccines, and careful epidemiological surveillance to detect possible outbreaks of epidemics.

\section{Rehabilitation Activities}

The recession of the flood waters increased rather than decreased the scope of the environmental sanitation activities. A large number of Public Health Service personnel worked over a prolonged period in controlling insect breeding and nuisances. This work required the use of much insecticide spraying equipment and large supplies of DDT, chlordan, oil, and other insecticides, some of which were delivered to the area by air transport. Initial emphasis was placed on fly control to prevent the possible spread of diseases such as typhoid and dysentery; and later emphasis, on mosquito control to assist local authorities in preventing an abnormal incidence of potential disease vectors. Entomological experts supervised the work after making on-the-spot surveys to determine what control measures would be most effective.

Another important problem facing local health authorities was the disposal of approximately 12,000 dead animals. This was accomplished principally by hauling the animals by truck to landfills for disposal by burial. Inspection of milk and food supplies was expanded to check all sources which had been subjected to contamination or spoilage, and to release only those products safe for consumption. Special measures were also taken to reinforce the normal rodent control programs of the flooded communities. Special checks of rat populations were made and rat poisons applied in those zones where rat populations were increasing because of migration or extraordinary exposure of food supplies. The importance of 
these various continuing activities is indicated by the fact that 1 month after the flood peak several of the Public Health Service technicians wore still on the job.

No abnormal incidence of any communicable disease was reported for any community in the area.

\section{Legislative Authority}

Authority for Public Health Service activities in assisting States at times of emergency is included in its authority for assisting States generally. Emergency assistance is customarily provided through the loan of specifically qualified personnel on State request under section 214 of the Public Health Service Act (Public Law 410, 78th Cong.).

More generally, section 311 of this act directs the Surgeon General to assist States and their political subdivisions in the prevention and suppression of communicable diseases and in the enforcement of local health regulations; also, the Interstate Quarantine Regulations of the Service, issued under section 361 of the act, authorize the Surgeon General to take special measures to prevent the interstate spread of the more important communicable diseases.

In the event of emergency or disaster, the President, under section 216 of the Public Health Service Act or under the Disaster Relief Act of 1950 (Public Law 875, 81st Cong.) may direct the utilization of the specialized personnel, equipment, and other facilities of the Service.

\section{Financing Emergency Assistance}

The Public Health Service has available, in the amount of $\$ 40,000$ annually, a special disaster and epidemic control fund, which is administered within the Communicable Disease Center of the Public Health Service. In years when one or more major disasters occur, especially disasters such as floods which create relatively great public health problems, this sum has not been adequate to meet the needs. In every instance, however, the Public Health Service has responded to requests from States to furnish at least the bare minimum of assistance necessary to prevent epidemics. Whenever necessary the Public Health Service has, with proper authority, utilized resources from regular operating programs-the emergency needs of States being given special priority in the sense that the prevention of mass epidemics is a Service function of the very highest importance.

Enactment of the Disaster Relief Act makes it possible for additional funds to be made available to finance Public Health Service emergency operations. The availability of such funds constitutes a kind of "insurance" and should make possible the undertaking of all essential emergency relief operations with a minimum of apprehension as to effects on regular program operations. And most important, the availability of funds through this act, in the form of grants to stricken communities will expedite their own recovery activities; thus the conditions which create major health hazards may be more quickly corrected. 